\title{
Diaphragmatic Plication for Patients with Acute Phase Phrenic Nerve Paralysis Following Lung Transplantation: A Case Report
}

\author{
Yasushi Shintani*, Masato Minami, Masayoshi Inoue, Soichiro Funaki, \\ Tomohiro Kawamura, Meinoshin Okumura \\ Department of General Thoracic Surgery, Osaka University Graduate School of Medicine, Osaka, Japan \\ Email: *yshintani@thoracic.med.osaka-u.ac.jp
}

Received 3 January 2016; accepted 21 February 2016; published 24 February 2016

Copyright (C) 2016 by authors and Scientific Research Publishing Inc.

This work is licensed under the Creative Commons Attribution International License (CC BY).

http://creativecommons.org/licenses/by/4.0/

(c) (i) Open Access

\section{Abstract}

Phrenic nerve injury can occur as a complication of lung transplantation. A 54-year-old man underwent single-lung transplantation due to interstitial pneumonia. The patient required circulatory support with venoarterial extracorporeal membrane oxygenation and was unable to be weaned from ventilatory support with nitric oxide. Although enhanced CT scanning showed stenotic anastomosis of the right pulmonary artery (PA), pulmonary angiograph findings revealed that PA flow was normal under sedation and considerably decreased with spontaneous breathing. Fluoroscopy showed that the right diaphragm moved inversely to the position of the left diaphragm, indicating that the right phrenic nerve was paralytic. We performed diaphragmatic plication 7 days after lung transplantation and weaning from ventilator support was accomplished soon thereafter. Phrenic nerve dysfunction is an important clinical problem following lung transplantation. In the present case, diaphragmatic plication was effective for treatment of circulatory failure due to phrenic nerve paralysis even in acute phase after lung transplantation.

\section{Keywords}

Lung Transplantation, Phrenic Nerve Paralysis, Diaphragmatic Plication, Circulatory Failure

\section{Backgrounds}

Damage to the phrenic nerve, either unilaterally or bilaterally, is a well-documented complication of cardiac

${ }^{*}$ Corresponding author.

How to cite this paper: Shintani, Y., Minami, M., Inoue, M., Funaki, S., Kawamura, T. and Okumura, M. (2016) Diaphragmatic Plication for Patients with Acute Phase Phrenic Nerve Paralysis Following Lung Transplantation: A Case Report. Open Journal of Organ Transplant Surgery, 6, 1-5. http://dx.doi.org/10.4236/ojots.2016.61001 
surgery, though less commonly reported following lung transplantation [1]. A lung transplantation procedure involves dissection of the mediastinum and manipulation of the pericardium, and also requires a cardiopulmonary bypass, thus phrenic nerve injury can occur as a complication [2], however, literature data on this complication are scarce. While some reports showed that phrenic nerve paralysis did not result in significantly adverse outcome [3] [4], others showed phrenic nerve paralysis caused severe respiratory failure and prolonged intensive care unit (ICU) and hospital stays [5]. We presented a patient with severe circulatory and respiratory failure due to phrenic nerve paralysis who underwent diaphragmatic plication during the acute phase after unilateral lung transplantation, which was highly effective for improvement of circulatory failure.

\section{Case Report}

\subsection{Case}

A 54-year-old man was diagnosed with nonspecific interstitial pneumonia (NSIP) and underwent right singlelung transplantation, with a lung ischemia time of 423 minutes. Following lung reperfusion, the patient showed moderate hypoxemia $\left(\mathrm{SpO}_{2}<80 \%\right)$, thus we provided venoarterial extracorporeal membrane oxygenation (VAECMO) as circulatory support. He was transferred to the ICU and could not undergo weaning from ventilator support with nitric oxide (NO). Furthermore, deep sedation was necessary, as awakening resulted in circulatory failure with increased blood pressure in the pulmonary artery (PA) as well as desaturation. Chest X-ray findings showed atelectasis of the upper lobe of the right lung on post-operative day (POD) 3 (Figure 1(a)), though VA-ECMO was removed the same day. Enhanced computed tomography (CT) showed anastomosis of the right PA that was stenotic (Figure 1(b)), thus pulmonary angiography was performed on POD 6, which indicated that PA flow found normal under deep sedation became considerably decreased during spontaneous respiration (Figure 1(c), Figure 1(d)). He also showed the paradoxical inward motion of the abdomen during inspiration. Fluoroscopy showed that the right diaphragm moved inversely to the left diaphragm, indicating that the right phrenic nerve was paralytic (Figure 2(a), Figure 2(b)).

\subsection{Diaphragmatic Plication for Phrenic Nerve Paralysis}

As we considered that this paradoxical breathing pattern affected the PA flow during spontaneous respiration, the patient underwent diaphragmatic plication on POD 7. The redundant diaphragm was elevated using 2 forceps and a Kelly clamp was placed along the desired suture line to create a diaphragmatic fold. A continuous su-

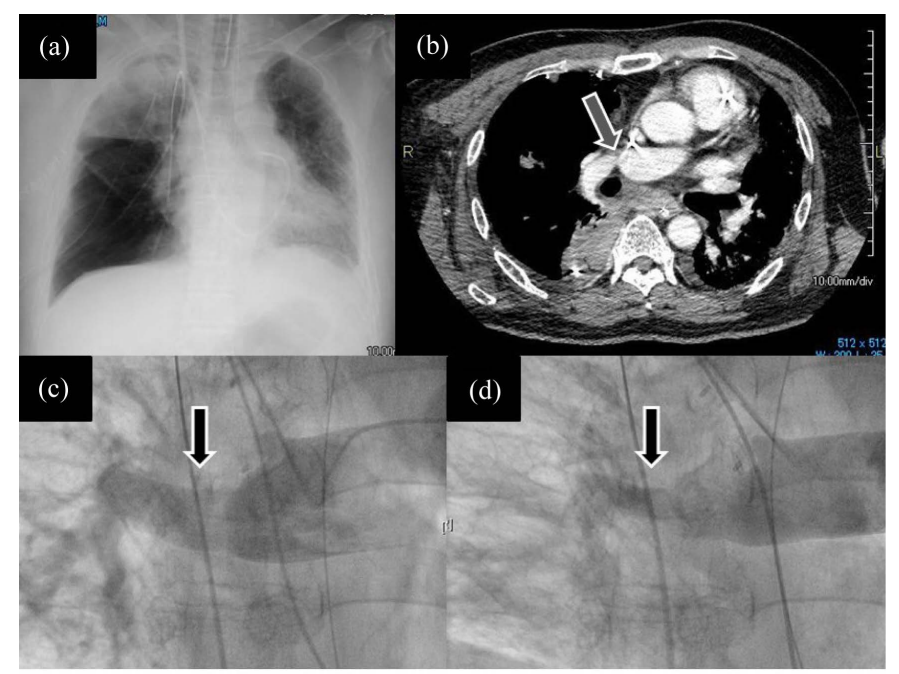

Figure 1. (a) Chest X-ray image showing atelectasis of the upper lobe of the right lung on post-operative day (POD) 3; (b) Enhanced computed tomography (CT) scan image showing stenotic anastomosis of the right pulmonary artery (PA) on POD 5 (arrow); (c) Pulmonary angiograph (PAG) showing normal PA flow (arrow) under deep sedation; (d) PAG showing considerably decreased PA flow (arrow) during spontaneous respiration. 


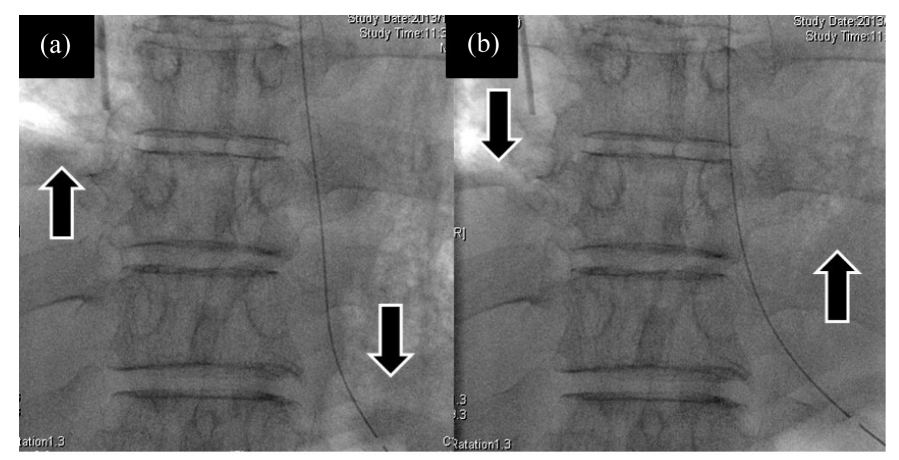

Figure 2. Fluoroscopy findings during spontaneous respiration showing inverse movement of the right diaphragm to the position of the left diaphragm. (a) Inspiration phase; (b)Expiration phase. Arrows indicate diaphragm position.

ture with 2-0 Prolenepledgeted with Dacron felt was passed along the base of the fold (Figure 3(a), Figure 3(b)). The right diaphragmatic plication resulted in weaning from ventilator support with NO. Chest X-ray findings showed gradual improvement of atelectasis of the upper lobe of the right lung (Figure 3(c), Figure 3(d)). A tracheostomy was then able to be performed on POD 9 because it was considered dangerous under unstable respiratory condition before diaphragmatic plication. Mechanical ventilation was discontinued on POD 28 following the tracheostomy and physical rehabilitation. The tracheostomy was then closed on POD 50 and the patient was discharged on POD 111.

\section{Discussion}

\subsection{Phrenic Nerve Paralysis after Lung Transplantation}

Incidence of phrenic nerve paralysis has been reported ranging from $3 \%$ to $30 \%$ after lung transplantation [2]-[4]. Operation-related phrenic nerve injury has been resulted from stretching during retraction of the sternum and manipulation of the pericardium, oppression for securing a field of view over a deep surgical site, or from ice slush hypothermic injury to phrenic nerves [5]. In this case, injury to the phrenic nerve might occur during the division of the pulmonary hilum or be caused by electrocautery for hemostasis. Diaphragmatic paralysis may initially be suspected because of failure to be weaned from mechanical ventilator support or by paradoxical movement of the diaphragms in a clinical examination. Diaphragmatic paralysis can be diagnosed by assessment of movement of the hemidiaphragms by physical examination of the chest wall and abdominal movement during inspiration, and fluoroscopy or ultrasound findings [6]. In the present patient, deep sedation was needed to maintain circulatory and respiratory conditions, thus a diagnosis of phrenic nerve paralysis was not possible until performing pulmonary angiography. The paradoxical breathing pattern affected the PA flow during spontaneous respiration, thus deep sedation was necessary to avoid circulatory failure. When awakening results in circulatory failure or desaturation after lung transplantation, diaphragmatic paralysis should be considered in the differential diagnosis of them (Table 1).

\subsection{Diaphragmatic Plication}

Diaphragmatic placation is performed to improve ventilator mechanics in cases of diaphragmatic paralysis, leading to a shorter duration of mechanical ventilation support and improved a respiratory function over the long term [4]. Although diaphragmatic placation has been reported to offer functional improvement in pulmonary function with low morbidity [7] [8], surgical procedure has larger risks for patient with severe circulatory and respiratory failure. In our case, since quick recovery from phrenic paralysis was not expected, the aim of diaphragmatic plication was to fix the right diaphragm for increased chest wall ventilation efficiency as well as avoid mediastinal flutter. Although the patient was dependent exclusively on chest wall motion for breathing after diaphragmatic plication, he was able to successfully undergo weaning from ventilatory support. Our findings show the feasibility of diaphragmatic plication for patients with severe circulatory and respiratory failure due to phrenic nerve paralysis in the acute phase after lung transplantation. 


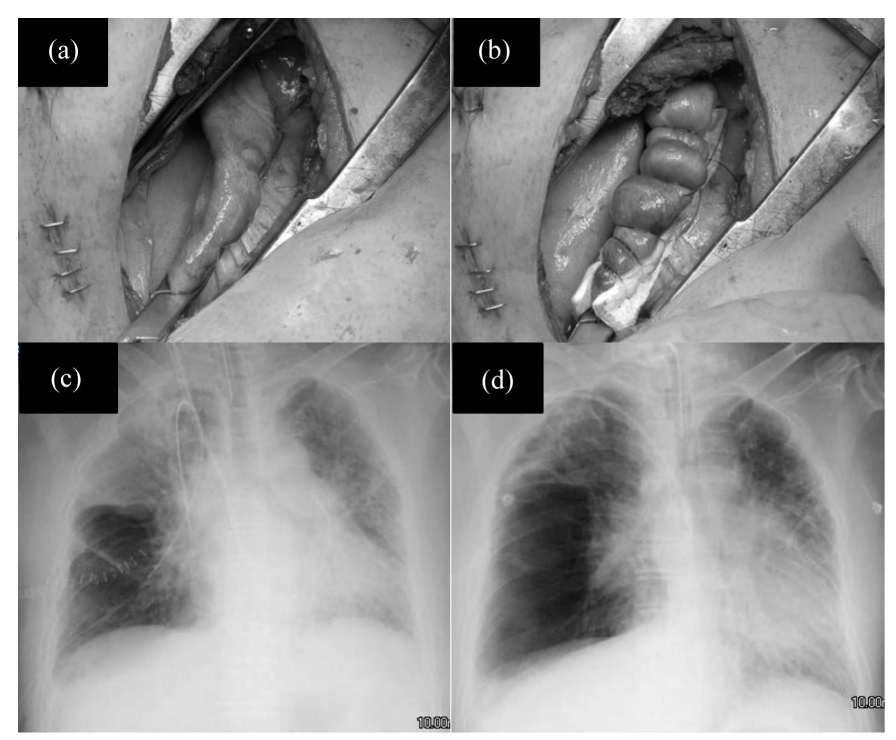

Figure 3. (a) Intraoperative view of diaphragmatic placation performed on POD 7. The redundant diaphragm was elevated and a Kelly clamp placed along the desired suture line to create a diaphragmatic fold; (b) A continuous suture with 2-0 Prolenepledgeted with Dacron felt was passed along the base of the fold; (c) Chest X-ray images showing gradual improvement of atelectasis of the upper lobe of the right lung. Image obtained prior to diaphragmatic placation; (d) Image obtained on POD 14 after lung transplantation (7 days after diaphragmatic plication).

Table 1. Features of acute phase phrenic nerve paralysis following lung transplantation.

Failure to be weaned from mechanical ventilation

Paradoxical movement of the abdomen during inspiration

Persistent atelectasis

Desaturation or circulatory failure caused by awakening

\section{Conclusion}

Phrenic nerve dysfunction is an important clinical problem following lung transplantation and has an influence on cardiopulmonary condition, especially on PA flow. Diaphragmatic plication for patients with acute phase phrenic nerve paralysis following lung transplantation was effective for treatment of circulatory failure.

\section{Consent}

Written informed consent was obtained from the patient for publication of this case report and any accompanying images.

\section{Conflicts of Interest}

The authors have no conflicts of interest to declare.

\section{References}

[1] Chandler, K.W., Rozas, C.J., Kory, R.C. and Goldman, A.L. (1984) Bilateral Diaphragmatic Paralysis Complicating Local Cardiac Hypothermia during Open Heart Surgery. The American Journal of Medicine, 77, 243-249. http://dx.doi.org/10.1016/0002-9343(84)90698-3

[2] Maziak, D.E., Maurer, J.R. and Kesten, S. (1996) Diaphragmatic Paralysis: A Complication of Lung Transplantation. The Annals of Thoracic Surgery, 61, 170-173. http://dx.doi.org/10.1016/0003-4975(95)00823-3 
[3] Sheridan Jr., P.H., Cheriyan, A., Doud, J., Dornseif, S.E., Montoya, A., Houck, J., Flisak, M.E., Walsh, J.M. and Garrity Jr., E.R., The Loyola University Lung Transplant Group (1995) Incidence of Phrenic Neuropathy after Isolated Lung Transplantation. The Journal of Heart and Lung Transplantation, 14, 684-691.

[4] Mogayzel Jr., P.J., Colombani, P.M., Crawford, T.O. and Yang, S.C. (2002) Bilateral Diaphragm Paralysis Following Lung Transplantation and Cardiac Surgery in a 17-Year-Old. The Journal of Heart and Lung Transplantation, 21, 710-712. http://dx.doi.org/10.1016/S1053-2498(01)00385-0

[5] Ferdinande, P., Bruyninckx, F., Van Raemdonck, D., Daenen, W. and Verleden, G. (2004) Leuven Lung Transplant G. Phrenic Nerve Dysfunction after Heart-Lung and Lung Transplantation. The Journal of Heart and Lung Transplantation, 23, 105-109. http://dx.doi.org/10.1016/S1053-2498(03)00068-8

[6] Groth, S.S. and Andrade, R.S. (2010) Diaphragm Plication for Eventration or Paralysis: A Review of the Literature. The Annals of Thoracic Surgery, 89, S2146-S2150. http://dx.doi.org/10.1016/j.athoracsur.2010.03.021

[7] Gazala, S., Hunt, I. and Bedard, E.L. (2012) Diaphragmatic Plication Offers Functional Improvement in Dyspnoea and Better Pulmonary Function with Low Morbidity. Interactive Cardiovascular and Thoracic Surgery, 15, 505-508. http://dx.doi.org/10.1093/icvts/ivs238

[8] Celik, S., Celik, M., Aydemir, B., Tunckaya, C., Okay, T. and Dogusoy, I. (2010) Long-Term Results of Diaphragmatic Plication in Adults with Unilateral Diaphragm Paralysis. Journal of Cardiothoracic Surgery, 5, 111. http://dx.doi.org/10.1186/1749-8090-5-111 